\title{
15. ELECTRICAL RESISTIVITY OF BASALTS FROM DSDP LEG 26
}

\author{
R. D. Hyndman, Department of Oceanography, and J. M. Ade-Hall, Department of Geology, \\ Dalhousie University, Halifax, Nova Scotia, Canada
}

\section{INTRODUCTION}

A knowledge of the electrical resistivity of ocean-floor rocks is important for the interpretation of field measurements of electrical resistivity and for an understanding of the composition and structure of these rocks. In situ measurement of sea-floor resistivity using artificial sources is possible despite the low-resistivity seawater (Coggon and Morrison, 1970). No surveys have been reported, but they may be expected in the near future. There have been a number of artificial source measurements on oceanic islands (Hermance et al., 1972). Natural electromagnetic induction has been extensively studied on oceanic islands: Hermance and Garland (1968) and Hermance (1973) on Iceland; Klein (1971) on Hawaii; Elvers et al. (1970) on Puerto Rico; Berdichevskiy and Chernyavskiy (1970) on Indian Ocean islands; and unpublished data on the Azores ( $\mathrm{J}$. F. Hermance, and R. Thayer, personal communication) and on Bermuda (D. I. Gough, personal communication). Deep ocean-floor magnetotelluric measurements have been reported from off California by Cox et al. (1970) and Greenhouse (1972), off Peru by Richards (1970), in the Arctic Ocean by Schneyer and Fonarev (1968), and in the Atlantic Ocean (R. P. Von Herzen, personal communication). Ocean-floor resistivity also has been estimated from the geomagneticinduction coast effect (Schmucker, 1970) although the effect is primarily due to the conductive seawater. These different approaches all suggest lower resistivity beneath the sea floor than generally exists beneath continents.

The electrical resistivity of most rocks decreases rapidly with increasing temperature so the lower seafloor resistivity may be associated with higher temperatures, compared to the same depth beneath continents. The higher temperatures are required by the similar surface-heat flow and the higher radioactive heat production in continental crustal rocks (Bullard, 1963; Clark and Ringwood, 1964; Sclater and Francheteau, 1970). A consistent electrical resistivity and thermal model for the crust and upper mantle beneath Iceland has been produced by Hermance and Grillot (1973). However, there is an indication of low resistivity at depths too shallow beneath the sea floor to be readily explained by high temperatures within rocks of the resistivity generally found in laboratory studies of basaltic and ultramafic rocks (Cox et al., 1970). Most laboratory resistivity measurements have been made on continental or oceanic-island samples, and it is becoming increasingly clear that the minor-element compositions and physical properties of such rocks are not representative of rocks beneath the deep-ocean floors. Thus, there is a need for a more extensive survey of the resis- tivity of ocean-floor rocks, particularly to see if they might be more conductive than previously thought. The Deep Sea Drilling Project provides a unique opportunity to obtain representative samples of upper crustal rocks.

The electrical resistivity of most dry basaltic rocks at low temperatures (less than $100^{\circ} \mathrm{C}$ ) ranges between $10^{3}$ and $10^{6} \mathrm{ohm}-\mathrm{m}$ (Coster, 1948; Khitarov and Slutskiy, 1965; Parkhomenko, 1967; and Bondarenko, 1968). Since most rocks to at least a depth of $5 \mathrm{~km}$ are likely saturated with aqueous solutions (Brace, 1971), laboratory measurements on saturated rocks are more relevant. The salinity of the saturating solution affects the resistivity, but not as much as might be expected since surface conductivity effects reduce the resistivity for low-salinity solutions (Brace et al., 1965; Keller and Frischknect, 1966). A large number of measurements of saturated continental volcanic rocks have been made at $1 \mathrm{~atm}$ pressure (Keller, 1966) and a few under pressure (Brace and Orange, 1968; Stesky and Brace, 1973). At oceanic-crustal temperatures and pressures $(0.5-2 \mathrm{~kb}$ and $0-100^{\circ} \mathrm{C}$ ) the continental basalts and gabbros have a resistivity from $10^{4}$ to $10^{5} \mathrm{ohm}-\mathrm{m}$ (one gabbro from Nahant, Massachusetts was much more conductive). Four basalt samples from Iceland reported by Hermance et al. (1972) have a very similar resistivity. However, five deep ocean-floor samples dredged from the Indian Ocean have significantly lower resistivities of $10^{2}$ to $2 \times 10^{3} \mathrm{ohm}-\mathrm{m}$ (Cox, 1971; Stesky and Brace, in preparation) as do three samples from DSDP sites. It thus seems that continental and oceanic-island basalts may be more resistive than ocean-floor basalts by a factor of 100.

\section{RESISTIVITY MEASUREMENTS}

Resistivity was measured to $2-\mathrm{kb}$ pressure and room temperature on core samples which were $2.5 \mathrm{~cm}$ in diameter and about $5-\mathrm{cm}$ in length. The ends were painted with silver conducting epoxy resin and the samples held between two aluminum electrodes of the same diameter. Both sample and electrodes were then encased in an impervious rubber jacket. The sampleelectrode face was perforated with holes leading to reservoirs in the electrodes to take up pore water squeezed from the sample. The design is similar to that of Brace et al. (1965). The ZrC layer they used at the electrode ends does not seem to be necessary (W. F. Brace, personal communication). The resistivity was measured at $100 \mathrm{~Hz}$ for all samples and an additional range of frequencies for some. There is very little frequency dependence, at least to $10 \mathrm{kHz}$. The measured resistivity became constant after changes in pressure in less than 10 minutes. 


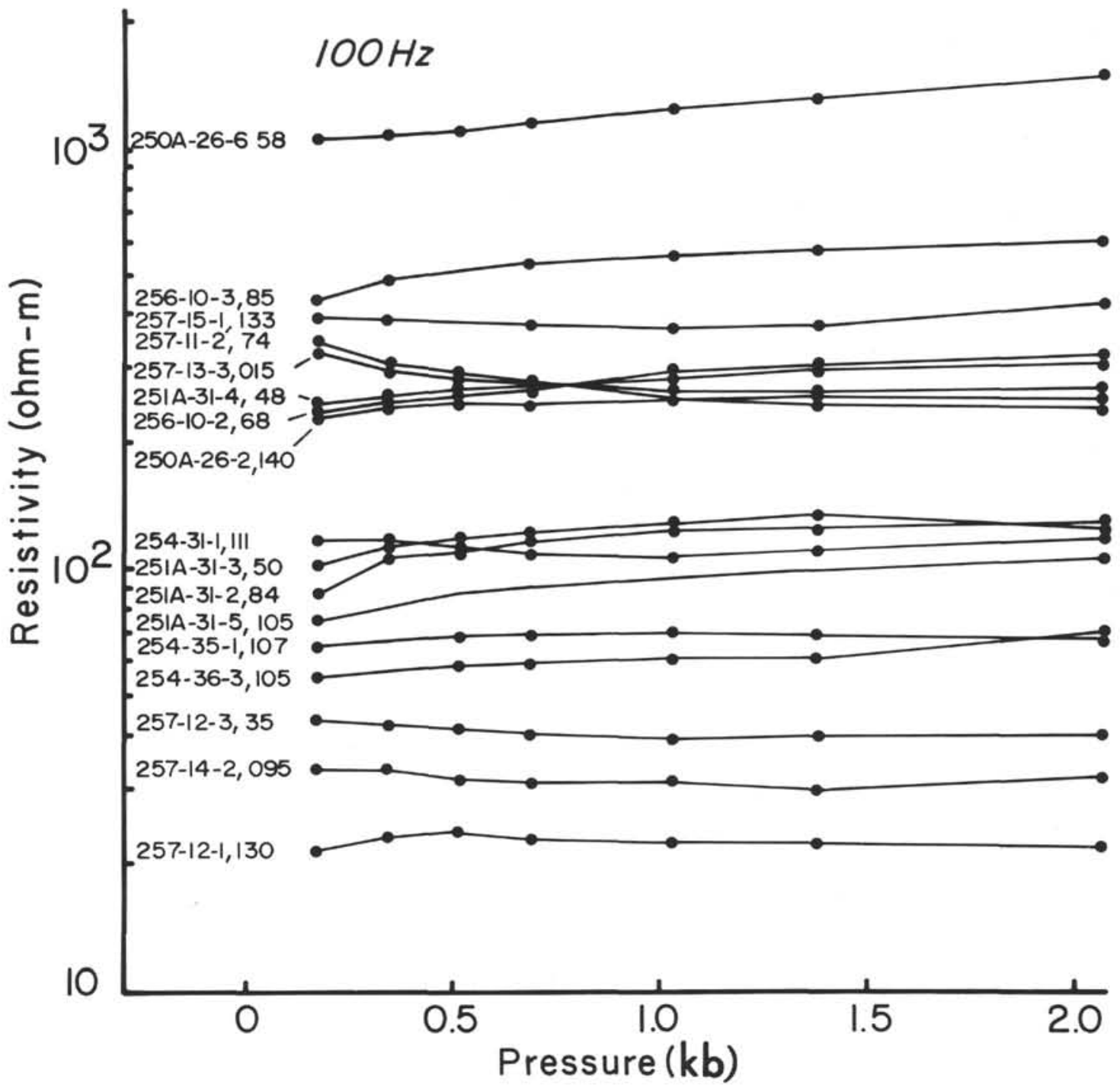

Figure 1. Resistivity of DSDP Leg 26 samples as a function of pressure.

The accuracy of resistivity measurement is about $10 \%$ and values are reproducible to $10 \%$ to $20 \%$. Pressure values are reproducible to $2 \%$.

The samples were saturated in seawater $(0.30 \mathrm{ohm}-\mathrm{m})$ for a minimum of 7 days before measurement which gave reproducible results for pressures above $0.25 \mathrm{~kb}$, suggesting fairly complete saturation. The water appears to be forced into any unfilled pores at moderate pressures in these samples. Samples can be saturated by placing them in a vacuum and then dropping them into water (Brace et al., 1965), but our experience is that shelf drying does not remove the water from nearly closed pore spaces so only the more open pores need to be resaturated. Oven heating and evacuating does remove some of the tightly held water which is difficult to restore. The possibility of incomplete saturation makes our resistivity measurements maximum values. The resistivity of the pore water in oceanic-crustal rocks is difficult to estimate but, at least at shallow depths, 0.30 ohm-m seawater should be reasonable.

The measured resistivity as a function of pressure, shown in Figure 1, ranges from 20 to $1000 \mathrm{ohm}-\mathrm{m}$. The values changed very little with pressure to $2 \mathrm{~kb}$, the more resistive samples increasing slightly, the less resistive remaining nearly constant. Two cores (257-11 and 25713) decreased in resistivity with increasing pressure at low pressures, which suggests to us that initially there had been incomplete saturation of these samples. The lack of a rapid increase in resistivity with increasing pressure is in marked contrast to virtually all of the continental and oceanic-island rocks previously reported. Brace et al. (1965) and Brace and Orange (1968) have argued that low resistivity and a small- or negativepressure effect indcates primarily mineral rather than pore-fluid conduction. The composition, particularly the metallic oxides and the conduction mechanism, are 
discussed in the next section. A histogram of numbers of samples versus resistivity at $2-\mathrm{kb}$ pressure is shown in Figure 2.

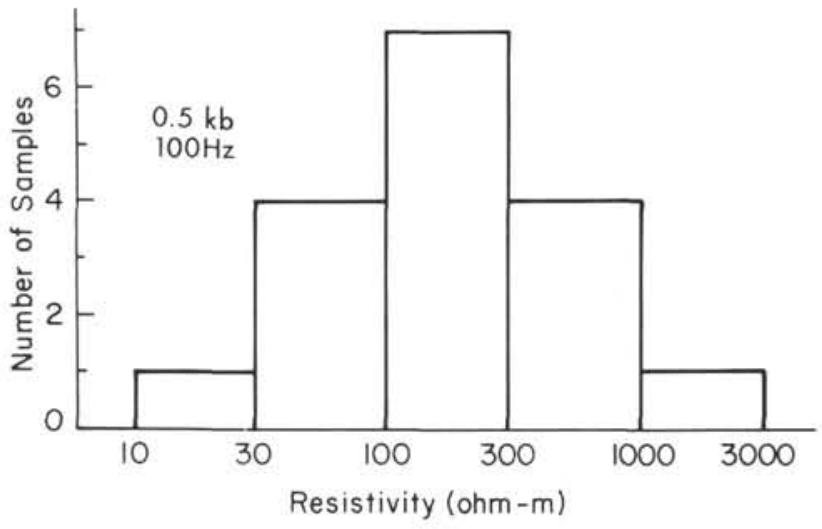

Figure 2. Histogram giving number of samples versus resistivity at $0.5 \mathrm{~kb}$ pressure.

\section{PETROLOGY AND ROCK MAGNETIC MEASUREMENTS}

To try to explain the low observed resistivity and its wide spread, the correlation of resistivity with a number of petrological and rock-magnetic parameters has been examined. The metallic minerals present were likely most important so they were studied through microscope examination of polished surfaces and through Curie temperature measurements.

Polished surfaces were prepared from specimens taken directly adjacent to the resistivity samples in all cases except one. The surfaces were polished with successively finer abrasives, finishing with $1 \mu$ diamond paste. They were examined using a Reichert Zeto Pan Pol ore microscope using an oil-immersion objective and an effective magnification of 1350 diameters. Careful note was taken of features indicative of the alteration state of the samples, in addition to more conventional observation of the primary oxide grains.

The variation of saturation magnetization with temperature was made using 10-mg chips from the samples used for the polished sections. The chips were held in a small furnace between the Faraday pole pieces of a 7.5-kg electromagnet. The samples were heated in air at rates in excess of $200^{\circ} \mathrm{C} / \mathrm{min}$ in order to reach initial Curie temperatures before alteration could take place in the many magnetically highly metastable samples. Changes in magnetic moment were recorded using a Cahn R 100 electrobalance and a BBN 815M XY plotter showing temperature on one axis. The results of these measurements allow us to propose a rather simple model to explain the electrical resistivity results.

We note first that the nature of the primary oxide phase of the basalt samples, always a titanomagnetite, and the quantity of this primary phase present do not relate obviously to the observed resistivity. Rather, it is the history of alteration after initial solidification that relates strongly to the resistivity. Samples containing disseminated hematite or possibly iron-hydroxides show low resistivity. Hematite (and hydroxides) are not primary minerals in basalts, but are formed either during high-temperature deuteric oxidation during initial cooling or later during "weathering" or hydrothermal alteration following burial by younger rocks. We are concerned with hematite and hydroxides that are distributed throughout the rock and not as in situ replacements for isolated primary oxide grains. Hematite in these conditions can occur in several ways:

1) As abundant, very fine particles in areas surrounding altered primary oxides; in silicates, generally, and particularly in areas of glass which frequently contain many tiny primary oxides. Hematite or hydroxides occurring in this form cause strong red, brown, or yellow internal reflections on a polished surface examined with incident light.

2) As continuous veins throughout the sample. Here the hematite is more concentrated and the characteristic white, high reflectivity of the mineral is seen.

3 ) In the replacement of ferromagnesian silicates, especially olivine. Very large areas up to $0.5 \mathrm{~mm}$ in diameter, rich in hematite, have been formed in this way in some samples.

Since the resistivity of hematite is much less than that of dry rocks (generally between $10^{-2}$ and $10^{2}$ ohm-m, Keller, 1966), the presence of continuous or nearly continuous hematite plus electrolyte paths in these altered basalts appears to lead to their unexpectedly low resistivity. This mineralogical explanation is consistent with the contention of Brace et al. (1965) and Brace and Orange (1968) that a nearly constant or decreasing resistivity with increasing pressure precludes conduction primarily by pore fluid.

To demonstrate a quantitative relationship between resistivity and disseminated hematite we have studied the magnetic properties of the samples. Two of the processes responsible for the formation of disseminated hematite, high-temperature deuteric oxidation and hydrothermal alteration, result in an increase in Curie temperatures of the primary oxide grains (Ade-Hall et al., 1971). In Figure 3 resistivity (at $0.5 \mathrm{~kb}$ ) is plotted against Curie temperature. There is clearly an inverse relationship, with a decrease in resistivity of a factor of 10 being associated with an increase in Curie temperature of about $200^{\circ} \mathrm{C}$. Resistivity of less than 120 ohm-m does not occur in samples with Curie points of less than $270^{\circ} \mathrm{C}$, but does occur in a few samples with Curie points between $270^{\circ} \mathrm{C}$ and $370^{\circ} \mathrm{C}$. All samples with resistivity less than $120 \mathrm{ohm}-\mathrm{m}$ are characterized by disseminated or other forms of secondary hematite.

\section{SUMMARY AND CONCLUSIONS}

The resistivity of seawater-saturated DSDP Leg 26 samples is low, covering a range from 10 to $10^{3} \mathrm{ohm}-\mathrm{m}$ at $0.5 \mathrm{~kb}$ (oceanic crustal pressure) with a mean of 140 ohm-m, assuming a log-normal distribution. The bulk resistivity that would be found by field measurements would depend on the direction of the measurement current relative to the orientation of the inhomogeneities. For example, if the inhomogeneities are 


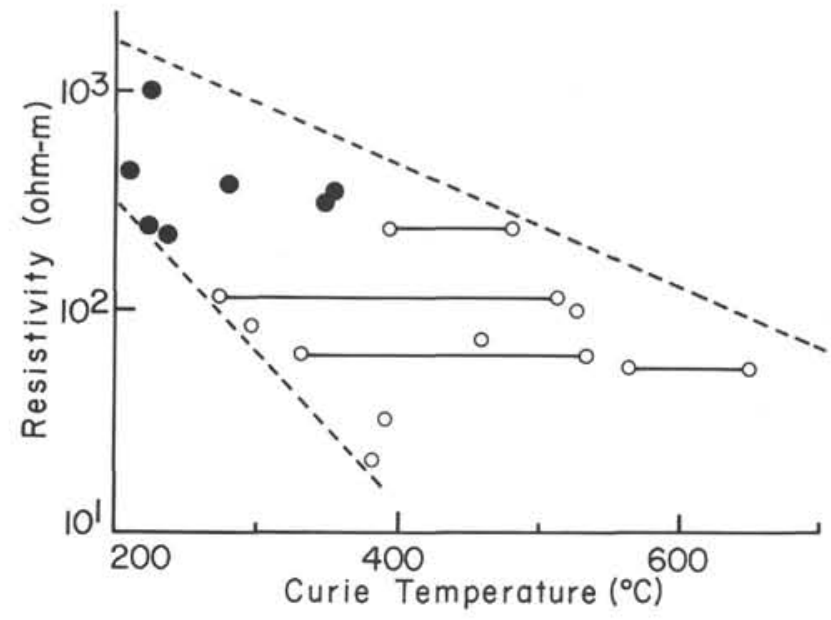

Figure 3. Resistivity at $0.5 \mathrm{~kb}$ versus Curie temperature. Open circles refer to samples containing secondary hematite. The circles joined by lines refer to samples with two Curie temperatures indicating that two magnetic phases are present. Solid circles refer to samples without secondary hematite.

approximately horizontal, say associated with lava flows, natural electromagnetic induction measurements would give approximately the parallel mean resistivity, $85 \mathrm{ohm}-\mathrm{m}$ for our material. The pressure dependence of resistivity is very small suggesting that mineral conduction is largely responsible for the observed low values. A clear correlation exists between low resistivity and the presence of various forms of secondary hematite. The correlation is expressed quantitatively by the rise in Curie temperature associated with the presence of secondary hematite. Conduction in the samples is through the combined effect of near-continuous conducting paths in the secondary hematite plus through the seawater electrolyte where the paths are broken.

\section{REFERENCES}

Ade-Hall, J. M., Palmer, H. C., and Hubbard, T.P., 1971. The magnetic and opaque petrological response of basalts to regional hydrothermal alteration: Geophys. J., v. 24, p. 137.

Berdichevskiy, M. N. and Chernyavskiy, G. A., 1970. Magnetotelluric sounding experiments on Indian Ocean islands: Phys. Solid Earth (Izv.), v. 8, p. 521.

Bondarenko, A. T., 1968. Generalization of data on the conductance of igneous rocks at high temperatures in connection with the structure of the crust and upper mantle: Dokl. Akad. Nauk. SSSR, v. 178, p. 20.

Brace, W. F., 1971. Resistivity of saturated crustal rocks to 40 km based on laboratory measurements. In Heacock, J. G., (Ed.), The structure and physical properties of the earth's crust: Am. Geophys. Union, Geophys. Monogr. Series, v. 14, p. 243.

Brace, W. F. and Orange, A. S., 1968. Further studies of the effect of pressure on electrical resistivity of rocks: J. Geophys. Res., v. 73, p. 5407.

Brace, W. F., Orange, A. S., and Madden, T. R., 1965. The effect of pressure on the electrical resistivity of watersaturated crystalline rocks: J. Geophys. Res., v. 70, p. 5669.
Bullard, E.C., 1963. The flow of heat through the floor of the ocean. In Hill, M. N., (Ed.), The sea: v. 3, New York (Interscience), p. 218.

Clark, S. P., Jr. and Ringwood, A. E., 1964. Density distribution and constitution of the mantle: Rev. Geophys., v. 2, p. 35.

Coggon, J. H. and Morrison, H. F., 1970. Electromagnetic investigation of the sea floor: Geophysics, v. 35, p. 476.

Coster, H. P., 1948. The electrical conductivity of rocks at high temperature: Roy. Astron. Soc. Monogr. Not., Geophys. Suppl., v. 5, p. 193.

Cox, C. S., 1971. The electrical conductivity of the oceanic lithosphere. In Heacock, J. A. (Ed.), The structure and physical properties of the earth's crust. Am. Geophy Union, Geophys. Monogr. Series, v. 14, p. 227.

Cox, C. S., Filloux, J. H., and Larsen, J. C., 1970. Electromagnetic studies of ocean currents and electrical conductivity below the ocean floor. In Maxwell, A. E., (Ed.), The sea: v. 4, New York (Interscience), p. 637.

Elvers, D., Perkins, D., and Holbrook, R., 1970. A survey of anomalous geomagnetic variations in Puerto Rico: U.S. Coast Geod. Surv. Operational Data Report DR-9.

Greenhouse, J. P., 1972. Geomagnetic time variations on the sea floor off southern California: Ph.D. Thesis, Univ. of California, San Diego.

Hermance, J. F., 1973. An electrical model for the subIcelandic crust: Geophysics, v. 38 , p. 3.

Hermance, J. F. and Garland, G. D., 1968. Magnetotelluric deep-sounding experiments in Iceland: Earth Planet. Sci. Lett., v. 4, p. 469.

Hermance, J. F. and Grillot, L. R., 1973. Constraints on temperatures beneath Iceland from magnetotelluric data: Workship on Electromagnetic Induction, Univ. of Edinburgh, Scotland, Sept. 20-27, 1972.

Hermance, J. F., Nur, A., and Bjornsson, S., 1972. Electrical properties of basalt: relation of laboratory to in situ measurements: J. Geophys. Res., v. 77, p. 1424.

Keller, G. V., 1966. Electrical properties of rocks and minerals. In Clark, S. P., Jr., (Ed.), Handbook of physical constants: Geol. Soc. Am. Mem., v. 97, p. 553.

Keller, G. V. and Frischknecht, F. C., 1966. Electrical methods in geophysical prospecting: New York (Pergamon Press).

Khitarov, N. I. and Slutskiy, A. B., 1965. The effect of pressure on the melting temperatures of albite and basalt (based on electroconductivity measurements): Geochem. Internatl., v. 2, p. 1934.

Klein, D. P., 1971. Geomagnetic time-variations on Hawaii Island and mantle electrical conductivity (abstract): Am. Geophys. Union Trans., EOS, v. 52, p. 824.

Parkhomenko, E. I., 1967. Electrical properties of rocks: New York (Plenum Press).

Richards, M. L., 1970. A study of electrical conductivity in the earth near Peru: Ph.D. Thesis, Univ. of California, San Diego.

Schmucker, U., 1970. Anomalies of geomagnetic variations in the southwestern United States: Scripps Inst. Oceanogr. Bull., v. 13.

Schneyer, V. S. and Fonarev, G. A., 1968. Some results of observations of magnetic variations at the surface and bottom of the ocean: Geomag. Aeron., v. 8, p. 479-480.

Sclater, J. G. and Francheteau, J., 1970. The implications of terrestrial heat flow observations on current tectonic and geochemical models of the crust and upper mantle of the earth: Geophys. J., v. 20, p. 509-542.

Stesky, R. M. and Brace, W. F., 1973. Electrical conductivity of serpentinized rocks to $6 \mathrm{~kb}$ : J. Geophys. Res. v. 78, p. 7614. 